\title{
Jamil Dakhlia, Politique people
}

Rosny-sous-bois, Bréal, 2008

\section{Pierre Leroux}

\section{OpenEdition}

\section{Journals}

Édition électronique

URL : http://journals.openedition.org/questionsdecommunication/1008

DOI : 10.4000/questionsdecommunication. 1008

ISSN : 2259-8901

\section{Éditeur}

Presses universitaires de Lorraine

\section{Édition imprimée}

Date de publication : 1 juillet 2009

Pagination : 467-468

ISBN : 978-2-86480-989-0

ISSN : 1633-5961

\section{Référence électronique}

Pierre Leroux, "Jamil Dakhlia, Politique people», Questions de communication [En ligne], 15 | 2009, mis en ligne le 17 janvier 2012, consulté le 22 septembre 2020. URL : http://journals.openedition.org/ questionsdecommunication/1008; DOI : https://doi.org/10.4000/questionsdecommunication.1008

Ce document a été généré automatiquement le 22 septembre 2020.

Tous droits réservés 


\title{
Jamil Dakhlia, Politique people
}

\author{
Rosny-sous-bois, Bréal, 2008
}

Pierre Leroux

\section{RÉFÉRENCE}

Jamil Dakhlia, Politique people. Rosny-sous-bois, Bréal, coll. Thèmes et débats Société, 2008,128 p.

1 Le titre accrocheur de cet ouvrage ne doit pas faire croire que l'auteur entend étudier comme un simple état de fait le thème à la mode de la " peopolisation de la politique ", bien au contraire. Jamil Dakhlia se livre à un examen des différents aspects d'un objet plus journalistique que scientifique en analysant ce qui contribue à la globalité d'un phénomène qu'il qualifie à juste titre de polymorphe. En effet, la peopolisation du politique réunit trois phénomènes différents et en partie convergents : la proximité mise en scène dans les médias des gens célèbres (people) et des politiques, l'intrusion de ces célébrités du spectacle dans l'univers de «la» politique, et les formes journalistiques de traitement de la politique fondées sur les commérages et le dévoilement (parfois consenti) de l'intimité du personnel politique.

2 La peopolisation se révèle donc difficile à cerner. S'agit-il d'un phénomène consubstantiel de la politique ou d'une réalité émergente? L'endogamie entre les univers du spectacle et de la politique peut prendre des formes multiples : soutien mutuel en campagne électorale, mais aussi de façon accrue fréquentation régulière et amicale voire parfois union maritale entre des personnalités du spectacle, de la politique ou des médias. L'engagement de personnalités du spectacle au côté des politiques est ancien mais, ces vingt dernières années, il a cependant pris des formes inédites et parfois autonomes: la politisation des célébrités peut aujourd'hui les amener à présenter symboliquement leur action comme un palliatif à certaines carences du politique. Si l'intrication de la politique et du spectacle est un truisme, les formes plus récentes de convergence entre les univers du spectacle et de la politique conduisent à souligner le renouveau des modalités empruntées. Les mises en scène de 
l'intimité du personnel politique relèvent aujourd'hui de stratégies de communication et de la mise en récit du politique (storytelling). D’usage relativement récent en France, mais s'inspirant des pratiques en usages dans d'autres pays, cette construction des personnages publics dispose de scènes d'exposition nouvelles et régulières avec les talk-shows télévisés apparus à la fin des années 90.

3 L'auteur opère un retour historique qui souligne le lien entre des formes anciennes de représentation du souverain et l'exposition contemporaine des acteurs politiques. Il insiste sur le pas franchi avec l'apparition de supports médiatiques se donnant pour objet principal la valorisation des personnalités du spectacle. Le Star System va servir de matrice à la représentation de " célébrités " politiques dès l'entre-deux guerre. Par la suite, l'invention des formats journalistiques de la presse populaire accentue cette tendance. Selon l'auteur, son extension tient autant à la logique économique de médias à la recherche de formes rencontrant le succès, qu'aux évolutions technologiques des médias. En devenant un média grand public à travers la multiplicité des canaux, la télévision est à même de proposer des formes de valorisation multiples des personnalités issues des univers les plus variés. Au tournant des années 2000, l'internet "décloisonne " les espaces d'information, s'affranchissant des limites inhérentes aux médias anciens par sa rapidité de réaction et son faible contrôle éditorial. Autrefois apanage d'une presse populaire et dévaluée, ce type de traitement du politique se généralise à tous les médias. Ces évolutions sont inscrites dans le cadre sociétal plus général dont Richard Sennet (Les tyrannies de l'intimité, trad. de l'américain par Antoine Berman et Rebecca Folkman, Paris, Éd. Le Seuil, 1995[1979]) avait analysé la dimension historique. Cependant, l'auteur souligne le frein qu'introduisent des législations plus ou moins attentives, selon les pays, à la protection de la vie privée. Le dernier chapitre de l'ouvrage est d'ailleurs consacré à une interrogation sur «la fin de l'exception française » qui découlerait moins de l'évolution du cadre juridique que de la conversion généralisée du personnel politique à des pratiques de valorisation, plus ou moins contrôlées, les rapprochant des célébrités; l'instrumentalisation de ce type de représentation s'enracinant autant dans le cadre institutionnel de la $\mathrm{V}^{\mathrm{e}}$ République que dans ce qui apparaît comme une forme de «modernité» de la communication politique.

Dans l'avant-dernier chapitre, l'auteur se fait l'écho du débat sur les conséquences pour la démocratie de la généralisation de la peopolisation du politique dans ces diverses dimensions. Produit des intérêts croisés des médias, de l'univers du spectacle et de l'univers politique, la peopolisation semble participer d'une dévalorisation de la politique. C'est ce chapitre qui est le moins convaincant, sans doute parce qu'une telle question mériterait de plus larges développements que ne le permet un ouvrage de synthèse. La vision de la politique produite par les médias devrait pour être analysée s'inscrire plus globalement dans la relation des citoyens à la politique, sans idéaliser par ailleurs la notion de "démocratie", jamais véritablement interrogée dans les constats alarmistes. Sans véritable élément d'enquête isolant les effets de ce type de représentation, le débat tourne autour des lieux communs sur d'éventuels effets négatifs des médias auquel on peut opposer des thèses plus "optimistes" leur attribuant un rôle pédagogique salutaire auprès du plus grand nombre. L'auteur a le mérite de relativiser certains de ces arguments, sans cependant pouvoir développer plus avant d'autres hypothèses. 
5 De ce tour d'horizon, on retiendra la volonté de l'auteur de prendre la mesure de la complexité et de l'intrication de logiques tant médiatiques que politiques impliquées dans la "peopolisation", et qui conduisent à ce qu'il appelle en conclusion "une reconfiguration de l'arène civique ».

\section{AUTEURS}

\section{PIERRE LEROUX}

CRAPE, université Rennes I

Pierre.Leroux@uco.fr 